\title{
Entendiendo el papel del sistema de factores de crecimiento similares a la insulina (IGF) en la regulación funcional del trofoblasto humano
}

\author{
Myriam Sánchez-Gómez ${ }^{1,2}$ \\ ${ }^{1}$ Miembro de Número, Academia Colombiana de Ciencias Exactas, Físicas y Naturales \\ ${ }^{2}$ Profesora Titular, Departamento de Química, Universidad Nacional de Colombia
}

\begin{abstract}
Resumen
El desarrollo normal de la placenta depende de la diferenciación e invasión del trofoblasto, el principal componente celular de la placenta. Durante este proceso, las células de trofoblasto realizan un programa complejo de diferenciación, originando varios linajes celulares que aseguran el desarrollo y sostenimiento de la gestación. La diferenciación del trofoblasto depende de una variedad de factores autocrinos y paracrinos, que a través de mecanismos específicos y finamente regulados, estimulan la expresión de un amplio número de genes e incrementan la producción de hormonas y factores de crecimiento tales como los factores de crecimiento similares a la insulina (IGF). Algunas patologías de la gestación se caracterizan por la diferenciación e invasión defectuosa del trofoblasto, que es más el resultado y no el origen de la enfermedad, el cual se desconoce en la mayoría de los casos. En esta revisión se discutirá el papel de la familia de factores de crecimiento IGF en la regulación del crecimiento, invasión y diferenciación del trofoblasto humano incluyendo los resultados de estudios a nivel molecular realizados en los últimos años en nuestro laboratorio, así como sus implicaciones en el entendimiento de la patogénesis de algunas enfermedades gestacionales.
\end{abstract}

Palabras clave: trofoblasto, Sistema IGF, Diferenciación, Invasión, ETG.

Understanding the role of the insulin-like growth factor (IGF) system in the functional regulation of the human trophoblast

\begin{abstract}
Normal placental development is dependent upon the differentiation and invasion of trophoblast, the main cellular component of the placenta. During this process, trophoblast cells undergo a complex program of differentiation originating several cellular subtypes to ensure the development and progress of human gestation. Trophoblast differentiation is under the control of many autocrine and paracrine factors, that finely tune specific mechanisms that stimulate the expression of a group of genes and increase the production of hormones, including the insulinlike growth factors (IGFs). Certain gestational pathologies are characterized by defective trophoblast differentiaiton and invasion, which is more the result but not the cause of the disease. In this review we will discuss some of the studies focused on the role of the IGF family of growth factors including recent findings in our laboratory and their implications for a better understanding of some gestational diseases.
\end{abstract}

Key words: Trophoblast, IGF system, Differentiation, Invasion, GTD.

\section{Introducción}

El desarrollo normal de la placenta depende de la diferenciación e invasión del trofoblasto, el principal componente celular de la placenta. Durante este proceso, las células de trofoblasto realizan un programa complejo de diferenciación, originando varios linajes celulares que aseguran el desarrollo y sostenimiento de la gestación. La diferenciación del trofoblasto depende de una variedad de factores autocrinos y paracrinos, que a través de mecanismos específicos y finamente regulados, estimulan la expresión de un amplio número de genes e incrementan la producción de hormonas y factores de crecimiento. Algunas patologías de la gestación se caracterizan por la diferenciación e invasión defectuosa del trofoblasto, que es más el resultado y no el origen de la enfermedad, el cual se desconoce en la mayoría de los casos.

El sistema de factores de crecimiento similares a la insulina (IGF) está relacionado con el desarrollo del organismo y mantenimiento de la función celular normal y se le ha

\section{Correspondencia:}

Myriam Sánchez-Gómez, mysanchezd@unal.edu.co

Recibido: 11 de marzo de 2014

Aceptado: 5 de mayo de 2014 
asociado con la formación de tumores y cáncer. Tanto IGF-I como IGF-II se encuentran en casi todos los tipos celulares de la placenta desde la sexta semana de gestación, y parecen estar involucrados en todos los aspectos de su desarrollo y función. Se conoce poco sobre el papel que desempeñan los factores de crecimiento y hormonas en la regulación de la diferenciación del trofoblasto humano. Varios estudios se han realizado empleando modelos animales, principalmente el murino, generando importante conocimiento sobre factores de transcripción involucrados en la conversión del citotrofoblasto velloso (vCTB) en sincitiotrofoblasto (STB) (Cross, 2000; Scott et al., 2000). Sin embargo, la relevancia de estos estudios en el humano no es clara, dadas las diferencias marcadas que se han identificado con el proceso de diferenciación de la placenta murina (Carter, 2007; Handwerger, 2010).

En esta revisión se discutirán los resultados de los estudios realizados durante los últimos 7 años en el Grupo de Investigación en Hormonas de la Universidad Nacional de Colombia, dirigidas hacia una mejor comprensión de los mecanismos de acción molecular de la familia de factores IGF en la regulación del crecimiento, invasión y diferenciación del trofoblasto humano. Se discutirán las implicaciones que estos hallazgos pueden tener en el origen y desarrollo de la Enfermedad Trofoblástica Gestacional (ETG), así como en la búsqueda de marcadores tumorales que permitan un diagnóstico temprano de la enfermedad.

\section{EI trofoblasto humano y su diferenciación}

Las células de trofoblasto hacen parte de la placenta y son las encargadas de invadir el endometrio materno durante el proceso de implantación del blastocisto. Durante este proceso de diferenciación e invasión, las células de trofoblasto se dividen rápidamente para formar la interfase entre la madre y el embrión, mientras que otras subpoblaciones trofoblásticas invaden la decidua materna remodelando las arterias de la pared uterina, conocidas como arterias espirales, para facilitar la expansión de los tejidos extraembrionarios y aumentar el flujo sanguíneo hacia la placenta y el embrión en desarrollo (Kliman \& Feinberg, 1990; Graham \& Lala, 1992).

El trofoblasto está compuesto por varias poblaciones con diferentes morfologías: el vCTB presente en el compartimento fetal y precursor del STB y el citotrofoblasto extravelloso (evCTB), precursor de la célula trofoblástica invasiva (Handwerger, 2010). Durante la morfogénesis del trofoblasto velloso, las células $\mathrm{VCTB}$ proliferan rápidamente y se introducen en el STB formando columnas celulares rodeadas de sincitio, dando lugar a las vellosidades primarias. En el desarrollo ulterior, las células mesodérmicas fetales penetran en el núcleo de las vellosidades primarias y crecen en dirección de la decidua materna, formando las vellosidades secundarias. Las células mesodérmicas de la parte central comienzan a diferenciarse en células sanguíneas y capilares sanguíneos formando un sistema capilar velloso, convirtiéndose en vellosidad terciaria. El trofoblasto extravelloso no participa directamente en la formación de las vellosidades, abandona la matriz extracelular, migra y forma las vellosidades coriónicas de anclaje, que son columnas de células no polarizadas que erosionan y penetran la barrera uterina. El evCTB rompe múltiples membranas basales (incluyendo el endometrio epitelial y glandular, vasos sanguíneos y células deciduales) y degrada la matriz extracelular intersticial del endometrio, hasta producir la invasión del estroma uterino y el remodelamiento de las arterias espirales. La capa de células epiteliales de la vellosidad placental, compuesta por células vCTB y STB, es la encargada de separar la circulación materna del interior de las vellosidades. Las células STB multinucleadas forman una capa continua que regula el intercambio de sustratos, gases y otros factores entre la circulación fetal y materna. Son el sitio de síntesis de hormonas esteroidales y factores de crecimiento, tales como el lactógeno placentario (LP), la hormona gonadotropina coriónica (hGC) y la variante placental de la hormona de crecimiento (hGHv) (Silva et al., 2002).

Numerosos estudios han evidenciado el papel de la hGC en la diferenciación trofoblástica. La hormona hGC es producida en grandes cantidades por el sincitiotrofoblasto donde de manera autocrina y paracrina incrementa la formación de sincitio. Además, se ha reportado que los efectos promotores de diferenciación del factor de crecimiento epidermal (EGF), el factor inhibitorio de leucemia (LIF), el factor de necrosis tumoral a (TNFa), el estradiol y glucocorticoides requieren de la participación de la hGC en sus efectos promotores de diferenciación (Yang et al., 2003), demostrándose así el papel central que realiza la hGC en este fenómeno. Otros factores críticos identificados dentro del proceso de diferenciación del trofoblasto incluyen, entre otros, la tensión de oxígeno (Robins et al 2007), modificaciones de la cromatina (Kimura et al., 2007) y mantenimiento de la integridad estructural (Handwerger, 2010).

\subsection{Enfermedad Trofoblástica Gestacional}

Varios estudios han demostrado anormalidades en el proceso de diferenciación de las células de trofoblasto, como en pre-eclampsia, retardo del crecimiento intrauterino y en la enfermedad trofobástica gestacional (ETG). La ETG comprende un espectro de tumores interrelacionados surgiendo de un desarrollo anormal del tejido trofoblástico. Esta enfermedad varía de relativamente benigna como la mola hidatidiforme (completa y parcial) hasta maligna como la mola invasiva y el coriocarcinoma (Seckl et al., 2000).La mola hidatidiforme consiste en una placenta anormal, caracterizada por vellosidades coriónicas grandes y edematosas, acompañadas de trofoblasto hiperproliferativo (Berkowitz 
\& Goldstein, 1998). El coriocarcinoma es uno de los tumores malignos de más rápido crecimiento e invasividad, debido a su alta afinidad y capacidad de angioinvasión, que conduce a metástasis extensas. Las bases moleculares del origen de la enfermedad o de su pronóstico se desconocen en su mayor parte. En la actualidad, su diagnóstico se basa en criterios clínicos y de histopatología, corroborados por los altos niveles circulantes de hGC, criterios que han demostrado ser insuficientes y con frecuencia contradictorios.

En colaboración con investigadores del Instituto Nacional de Salud y del Instituto Materno Infantil, nuestro laboratorio adelantó entre los años 2002-2004 un estudio sobre los aspectos clínicos, genéticos y bioquímicos de la ETG. A nivel molecular, se evidenciaron alteraciones en el sistema de factores de crecimiento similares a la insulina (IGF) en pacientes con diagnóstico de mola hidatidiforme. El análisis del tejido tumoral mostró una elevada expresión del factor de crecimiento similar a la insulina tipo II (IGF-II) y de su receptor tipo I (IGF-IR), lo que se acompañó de niveles elevados de IGF-II en el suero de las pacientes, en comparación con abortos no molares de la misma edad gestacional (Cortés et al 2003; Sánchez, 2006]. Lo anterior puso en evidencia el rol potencial de esta familia de factores de crecimiento en el desarrollo de esta patología, desafortunadamente poco visible pero que constituye un problema de salud pública en nuestro país.

\section{El sistema de factores de crecimiento similares a la insulina}

La familia de factores de crecimiento similares a la insulina (IGF) está organizada como una compleja red regulatoria a nivel celular y sub-celular. En el humano, el sistema IGF tiene un papel fundamental en el desarrollo del organismo y mantenimiento de la función celular normal tanto en la etapa fetal como postnatal. Está constituido por los ligandos (IGF-I e IGF-II), receptores de superficie celular que median los efectos biológicos de los IGFs, incluyendo el receptor para IGF-I (IGF-IR), receptor IGF-II/M6P (IGF-IIR), el receptor de insulina (InsR) y receptores híbridos IGF-IR/InsR, además de seis proteínas de unión a IGFs (IGFBPs) (LeRoith et al., 1995, Denley et al., 2005). El principal mediador de las actividades celulares de los IGFs es el receptor IGF-IR, una proteína transmembranal con actividad tirosina quinasa, formada por dos cadenas a y dos cadenas b unidas a través de varios enlaces bisulfuro. La proteína madura posee mayor afinidad por IGF-I que por IGF-II (Favelyukis et al 2001). El receptor IGF-II-R posee un extenso dominio extracelular y no presenta actividad tirosina quinasa. Se une con mayor afinidad a IGF-II que a IGF-I. Este receptor no une insulina pero sí actúa como un receptor de ligandos con manosa-6 fosfato. El receptor de insulina existe en dos isoformas, InsR-A e InsR-B, derivadas de "splicing alternativo del exón
11 del gen del receptor. InsR-A une al IGF-II con la misma afinidad que enlaza la insulina, en tanto que InsR-B une débilmente al IGF-II (LeRoith \& Roberts, 2003).

Las similaridades estructurales entre el receptor de IGF y el receptor de insulina, permiten la formación de receptores híbridos, en donde una cadena IGF-IR $\alpha \beta$ está conectada a una cadena InsR-A o InsR-B. Cuando se coexpresan los receptores de IGF y de insulina en la misma célula, estos receptores híbridos pueden formarse aleatoriamente y el homo-receptor menos abundante se encontrará predominantemente formando parte de ellos. Los receptores híbridos, pueden ser sobreexpresados en una variedad de células tumorales como resultado de la sobre-expresión de los receptores para IGF-I e Insulina (Pandini et al., 2002), sin embargo, se conoce muy poco sobre su importancia en la transducción de señales $\mathrm{y}$ de los efectos biológicos que pueden estar modulando.

\subsection{El sistema IGF y el desarrollo de la placenta}

Los IGFs son reguladores importantes del desarrollo adecuado de la placenta y del feto (Lala et al., 1998). La expresión de los ligandos y sus receptores en las membranas placentales, sugiere mecanismos de acción de tipo autocrino y/o paracrino en el control de las propiedades funcionales de células trofoblásticas [Hamilton et al 1998]. Tanto el IGF-I como el IGF-II se encuentran en casi todos los tipos celulares de la placenta desde la sexta semana de gestación, y parecen estar involucrados en todos los aspectos de su desarrollo y función. Se ha demostrado que los IGFs están presentes en las vellosidades coriónicas placentales (citotrofoblasto, núcleo mesodérmico y endotelio), siendo el IGF-II más abundante en trofoblasto. El IGF-II se produce aproximadamente desde la sexta semana del embarazo desde el evCTB, no cruza la placenta hacia la circulación fetal pero puede regular el crecimiento placentario. Igualmente, podría estar relacionado con el proceso de invasión del trofoblasto extravelloso in vitro (Zygmunt et al., 2005).

Se sabe que IGF-I e IGF-II incrementan la proliferación y supervivencia de fibroblastos placentales y que pueden rescatar estas células de la apoptosis. Muchos estudios reportan el incremento en suero de estos dos factores durante el embarazo al igual que el aumento de los niveles del mRNA del IGF-I y del IGF-II (Forbes et al., 2008). El IGF-II tiene profundos efectos en el desarrollo prenatal y su desregulación puede estar relacionada con varias patologías durante la gestación. Sumado a esto, sus altos niveles en circulación durante el embarazo, mucho más que los de IGF-I, lo convierte en el ligando del sistema IGF más importante durante la gestación.

En cuanto a la presencia de los receptores IGF, se ha demostrado que el IGF-IR se localiza en todos los tipos celulares placentarios incluyendo el trofoblasto, el endotelio 
velloso y el núcleo mesenquimal, encontrándose también receptores híbridos con altas afinidades por el IGF-II (McKinnon et al., 2001). Se sabe que InsR-A se expresa en los tejidos fetales y en ciertos tumores y tiene efectos mitogénicos, en cambio los efectos de InsR-B son más metabólicos, expresándose abundantemente en tejidos adultos (Pandini et al, 2002).

El receptor tipo II se expresa en la placenta, en las membranas plasmáticas del trofoblasto, pero puede ser fragmentado resultando en la liberación de una forma soluble, la cual al unirse al IGF-II conduciría a su degradación, aunque en otros trabajos se ha mostrado su posible actividad en vías de señalización intracelular (McKinnon et al., 2001). Finalmente, en lo referente a las proteínas de unión a IGFs, se ha establecido que la placenta humana no expresa IGFBP-1 la cual es la proteína de unión de mayor expresión en el endometrio decidualizado, en tanto que IGFBP-3 se expresa en grandes cantidades en el estroma velloso del trofoblasto. Las funciones regulatorias de estas proteínas en el normal desarrollo de la placenta requieren aún de más estudios.

\subsection{Papel del IGF-II en la regulación de la invasion de celulas de coriocarcinoma}

El mecanismo por medio del cual el IGF-II ejerce sus acciones en las células de trofoblasto ha sido un tema controversial. Inicialmente se postuló al receptor IGF-II/M-6P dada su alta afinidad de unión por IGF-II (Mackinnon et al, 2001), sin embargo, numerosos estudios lo han descrito como un receptor encargado de la internalización de IGF-II y de su degradación, por lo tanto con una función inhibitoria. Otros investigadores han postulado que las acciones del IGF-II son mediadas por el IGF-IR (Pandini et al, 2002).

La expresión de IGF-II en tumores provenientes de mola hidatidiforme se ha encontrado incrementada en comparación con placentas de abortos espontaneos de primer trimestre, lo que plantea un papel para este factor en la patogénesis de la enfermedad y su malignización. El estudio de casos de coriocarcinoma, forma maligna del trofoblasto, han estado limitados por la rápida progresión a la metástasis dificultando el diagnóstico primario del tumor, por lo cual la investigación se ha centrado en líneas celulares, tales como BeWo, JEG-3, JAR, que expresan los miembros del sistema IGF.

En un estudio realizado por nosotros se demostró que tanto IGF-I como IGF-II regulan la invasión de células de coriocarcinoma, pero a través de diferentes mecanismos. Aunque ambos receptores activan en común las vías de señalización PI3-K y MAPK, fosforilando las proteínas Akt y ERK, se pudo establecer que el IGF-II media sus efectos activando el receptor de insulina (InsR), mientras el IGF-I lo hace a través del IGF-IR (Díaz et al., 2007). En concordancia con lo anterior, se encontró que IGF-II y en menor proporción IGF-I, son capaces de estimular la secreción de la metaloproteasa de matriz extracelular MMP9 y el activador de plasminógeno tipo urokinasa (uPA) en células de coriocarcinoma (Díaz, 2006; Pinzón et al, 2007). Una adecuada invasión por parte del trofoblasto es vital para el establecimiento del embarazo (Bischof et al., 2001). Este comportamiento invasivo es debido a la habilidad del evCTBs de secretar metaloproteasas (MMPs), mientras que sus inhibidores (TIMPs) inhiben esta invasión en el espacio extracelular. Tanto la MMP-9 como la MMP-2 son secretadas durante el primer trimestre de embarazo por el trofoblasto y participan en los procesos invasivos de éste. Varios estudios han demostrado que la síntesis y activación de la MMP-2 y MMP-9 son requeridas para la invasión trofoblástica (StaunRam et al, 2004).

Nuestros resultados demostraron la expresión de las dos isoformas de InsR en los tejidos molares y en las células JEG-3, y si tenemos en cuenta los altos niveles de expresión de IGF-II en los tejidos y su correspondencia en el suero, resulta plausible atribuir al IGF-II un importante papel regulador de las propiedades metastáticas de las células de coriocarcinoma. Se descartó que los efectos de IGF-II se llevaran a cabo a través de los receptores híbridos, ya que no se observó la fosforilación/activación del IGF-IR al estimular las células con IGF-II (Díaz et al.,2007).

\subsection{Papel de la familia IGF en la regulacion de la proliferacion e invasion del trofoblasto}

Se ha demostrado que el vCTB, caracterizado por su alta capacidad invasiva, expresa los niveles más altos de IGFII en la placenta, mientras que el STB lo expresa a muy bajos niveles (Han \& Carter, 2000). Numerosos estudios se han llevado a cabo empleando la línea celular HTR8/ SVneo, derivada de células evCTB de placenta humana de primer trimestre e inmortalizada con el antígeno T40 grande del virus de simio (SV40 Tag) (Graham et al., 1993). Estas células presentan un fenotipo hiperproliferativo e hiperinvasivo y morfológicamente tienen una identidad epitelial que corresponde a su origen trofoblástico.

Se sabe que las células HTR8/SVneo co-expresan los receptores IGF-IR e InsR, dando lugar a la formación de receptores híbridos IGF-I/InsR, cuya probabilidad de formación está determinada por los niveles de expresión de los receptores de IGF-I e insulina (Belfiore et al., 2009). En un trabajo en nuestro laboratorio se investigó el papel de los receptores híbridos en las acciones de los IGFs, modificando el equilibrio de los homo-receptores, mediante silenciamiento transitorio con RNA interferente (siRNA) (Santa Cruz Biotechnology). Al silenciar el receptor IGFIR se encontró una atenuación en los efectos proliferativos de IGF-I e IGF-II, en comparación con las células no 
silenciadas (Freyre, 2010), mientras que al silenciar el receptor de insulina, se observó la sobre-activación de la vía MAPK y el incremento en los efectos proliferativos del IGF-I evaluados por medio del método colorimétrico MTT. Lo anterior evidenció el equilibrio dinámico existente entre los dos receptores tirosina quinasa y el papel del InsR en la regulación de los efectos de los IGFs. En una línea celular que expresa predominantemente el receptor de insulina, en particular la isoforma InsR-A, al disminuir su expresión aumenta la probabilidad de formación de homo-receptores IGF-IR y disminuye la de homo-receptores InsR, lo que podría explicar el aumento en las señales mitogénicas de IGF-I en el modelo celular silenciado en InsR. Lo anterior pone en evidencia que los receptores IGF-IR e InsR están estrechamente relacionados en la regulación de la transducción de señales moleculares de los ligandos IGF y que la proporción de receptores es clave en la regulación de la intensidad de la señal y en la potencia del efecto mitogénico de los ligandos (Vallejo, 2011).

A nivel de las acciones de los IGFs sobre la capacidad invasiva de las células HTR8/Svneo, empleando cámaras de Boyden recubiertas con Matrigel y secreción de la metaloproteasa MMP-9, se encontró en el modelo silvestre, que tanto IGF-I como IGF-II son capaces de estimular invasión celular aunque los mayores efectos a nivel de secreción de MMP-9 se observan con IGF-II. En la Figura 1 se muestran los resultados obtenidos para las células silenciadas (Vallejo et al, 2014).

En conjunto, estos resultados sugieren que los receptores híbridos InsR/IGF-IR son los principales mediadores de la invasión inducida por IGF-I/IGF-II en la línea celular HTR8/SVneo, contrastando con lo que ocurre en las células de coriocarcinoma JEG-3, donde IGF-II se vuelve el ligando importante para la invasión señalizando a través del receptor de Insulina. Estos cambios podrían derivarse de alteraciones en el equilibrio de los receptores híbridos por la sobreexpresión del receptor InsR, dando como resultado una mayor proporción de homo-receptores de InsR y una baja en la disponibilidad de los hetero-receptores IGF-IR/InsR en coriocarcinoma.

La sobreexpresión de IGF-I, IGF-II o de sus receptores es un evento presente en la malignización celular y explica en parte la proliferación descontrolada característica del cáncer (Hanahan \& Weinberg, 2000). Varios estudios han asociado al sistema IGF con el desarrollo de tumores y carcinogénesis en varios tipos celulares (LeRoith \& Roberts, 2003, Frasca et al., 2008, Gallagher \& LeRoith, 2011, Singh et al 2014). En muchos tipos de cáncer se ha observado la sobreexpresión del receptor IGF-IR, de los ligandos IGF-II e IGF-I y de diferentes combinanciones de las seis proteínas de unión a IGF (IGFBP1-6) (Samani et al, 2007; Bruchin \& Werner, 2013). Numerosos estudios realizados en la última década

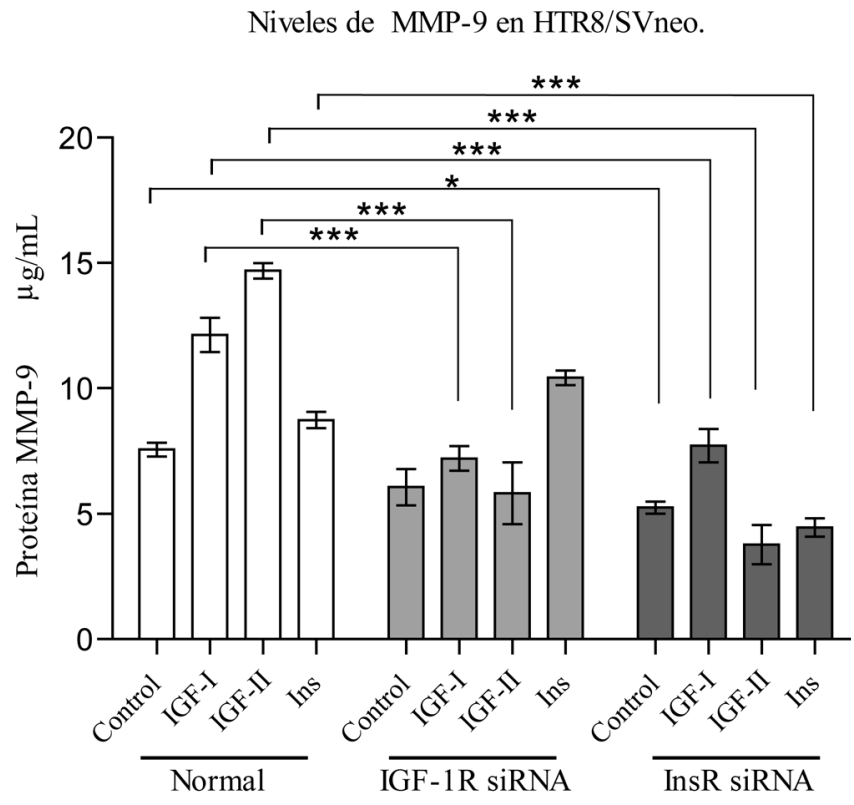

Figura 1. Efecto del silenciamiento del los receptores IGR-IR e InsR en la secreción de MMP-9.

Ensayo inmunoenzimático para la cuantificación de MMP-9 en medios condicionados. La significancia estadística fue determinada usando ANOVA y la prueba de múltiples comparaciones de Bonferroni. La significancia estadística usando como control la pareja de células apropiada control-transfectada es representada así: *, $P<0.05 ; * *, P<0.01 ; * * *, P<0.001$.

han mostrado anormalidades en la expresión del receptor de insulina en varios tipos de cáncer. Recientemente se reportó alteración en el mecanismo de "splicing" del gen del receptor InsR en células de cáncer, incrementándose la relación InsR-A/InsR y por lo tanto la respuesta celular a los IGFs e insulina circulantes (Belfiore et al., 2009). Aunque los IGFs no son en sí mismos factores tumorogénicos, la expresión elevada de IGF-II, como en el caso de pérdida de impronta (Pavelic et al., 2002) puede contribuir al desarrollo de ciertas patologías ginecológicas como el cáncer de ovario (Murphy et al., 2006).

Los anteriores resultados abren un panorama interesante de investigación, pues en la comparación entre el trofoblasto y su forma maligna, el coriocarcinoma, es posible encontrar claves para comprender el origen y desarrollo del crecimiento maligno. El comportamiento innato del trofoblasto muestra muchas características en común con células tumorales y metastáticas, tales como el alto nivel de proliferación, invasión, evasión de los efectores del sistema inmune, así como similitud en múltiples circuitos de señalización intracelular (Ferreti et al., 2007). No obstante, a diferencia de lo que ocurre en células malignas, los procesos celulares en el trofoblasto se encuentran altamente controlados y regulados espacial y temporalmente. Identificando las principales vías 
de señalización cuya desregulación permite a las células tumorales desarrollar habilidades para evadir el control del crecimiento y la invasión, se tendrán blancos terapéuticos promisorios para el desarrollo de nuevas estrategias antitumorales para la detección, control y tratamiento del proceso de metástasis.

\subsection{Papel de los factores de crecimiento similares a la insulina en la diferenciacion del trofoblasto}

Como se mencionó previamente, el proceso de diferenciación de las células trofoblásticas es fundamental para un desarrollo exitoso de la gestación. Es un proceso complejo que toma lugar rápidamente después de la implantación, donde a través de una serie de eventos coordinados en la interfase feto-maternal, las células madre de trofoblasto experimentan una extensiva diferenciación. Se reconocen dos vías principales para la diferenciación: la vía vellosa o de fusión y la vía extravellosa o invasiva (Handwerger, 2010). Varios sistemas in vitro se han desarrollado para el estudio de la fusión de células de trofoblasto, entre ellos, células de trofoblasto primario aisladas de placenta fusionada espontáneamente, o líneas celulares de coriocarcinoma como BeWo o JAR, que se caracterizan por un proceso incompleto de diferenciación (Aronow et al, 2001; Huppertz et al., 2007; Handwerger, 2010).
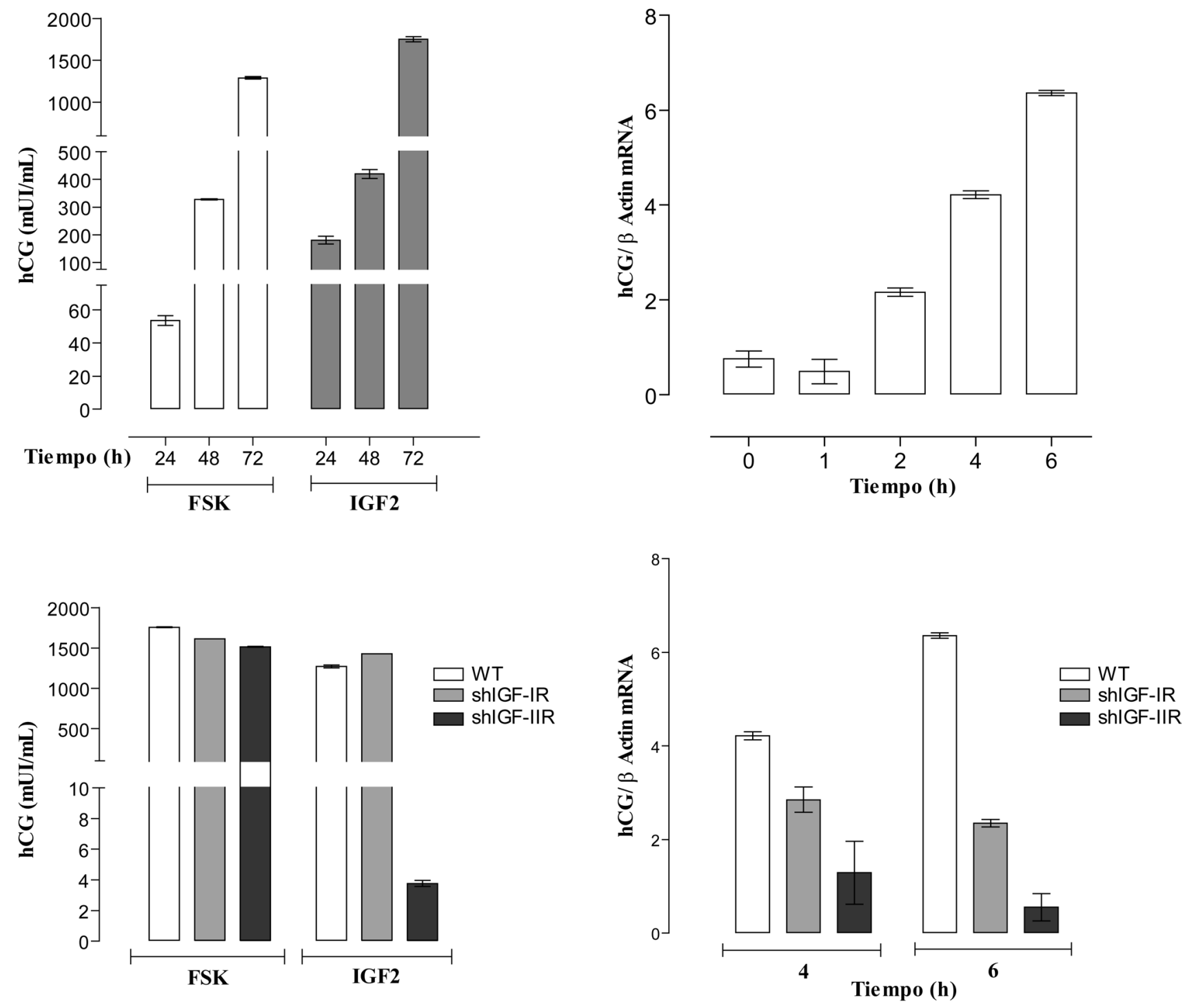

Figura 2. Niveles de secreción de hCG (IRMA) y de transcritos de hGC $\beta$ (qPCR) en células estimuladas con FSK(25 $\mu$ M) e IGF-II (10 nM). Panel superior) Células HTR8/SVneo (WT). Panel inferior) Células con silenciamiento estable de los receptores IGF-IR (shIGFIR) y IGF-IIR (shIGF-IIR). Los niveles de hGC se determinaron mediante IRMA y los transcritos de hGC $\beta$ mediante qPCR, relativos al gen casero $\beta$ Actina. Los valores corresponden al promedio de 3 determinaciones. 
Para el estudio in vitro de la diferenciación trofoblástica, se han empleado modelos celulares tales como BeWo, que aunque es una forma de coriocarcinoma está parcialmente diferenciada. Nosotros adelantamos un estudio utilizando células de la línea HTR8/SVneo, un modelo fenotípicamente más cercano al trofoblasto normal, induciendo diferenciación por estímulo con Forskolina (FSK), compuesto de origen natural agonista de la enzima adenilato ciclasa, lo cual resulta en la elevación de los niveles intracelulares de AMP cíclico. Los resultados mostraron que los niveles de expresión del mRNA de IGF-II y del receptor IGF-IIR en células HTR8/ SVneo se elevan significativamente después de $72 \mathrm{hr}$ de aplicado el inductor FSK y notablemente, el estímulo con IGF-II solo y en combinación con FSK, también incrementa los transcritos de IGF-IIR, evidenciando un papel potencial del eje IGF-II/IGF-IIR en diferenciación trofoblástica (Freyre SI, 2010; Cabezas et al., 2011).

Un hecho conocido es el incremento en los niveles de secreción de la hormona hGC a lo largo de la diferenciación. De manera novedosa encontramos que IGF-II estimula la transcripción y la secreción de la hormona hGC, como se muestra en la Figura 2. Posiblemente la glicoproteína sintetizada se almacena en gránulos de secreción hasta el momento de su liberación para su consecuente función biológica. Este efecto fue específico para IGF-II ya que cultivos estimulados con IGF-I no mostraron incremento en hGC (Freyre SI, 2010).
Los anteriores resultados, por demás novedosos, mostraron la relación entre IGF-II y la transcripción de hGC, resultando de interés identificar los receptores involucrados. Para ello se obtuvieron líneas celulares establemente silenciadas por transfección con una combinación de plásmidos lentivirales shRNA, diseñados específicamente contra IGF-IR e IGF-IIR (Santa Cruz Biotechnology). Se demostró que la carencia del receptor IGF-IIR resultaba en una drástica disminución en la expresión y secreción de la hormona (Figura 2) (Alarcón, 2011). Como se ha mencionado, el mecanismo de acción del IGF-IIR ha sido objeto de controversia, principalmente por la ausencia de un dominio intracelular de señalización. Se le ha atribuído una función reguladora de la biodisponibilidad de IGF-II mediante internalización vía endosomal y degradación ulterior (Kreiling et al., 2005). No obstante, estudios recientes dan soporte al papel del IGF-IIR en la activiación de cascadas de señalización a través de la activación de esfingosina quinasa (SK) y la transactivación de receptores acoplados a proteína G (El-Shewy, et al., 2007).

Se ha descrito que la síntesis de hGC está regulada por varios factores independientes, incluyendo la hormona liberadora de gonadotropina $(\mathrm{GnRH})$, leptina y varias citokinas que la estimulan mientras que la progesterona y el estradiol la inhiben (Bischof \& Irminger-Finger, 2005). Se ha descrito que el gen hGC $\beta$ posee dos sitios funcionales de unión al factor de transcripción ETS2 cercanos al sitio de inicio de la transcripción, que son cruciales para la regulación de la
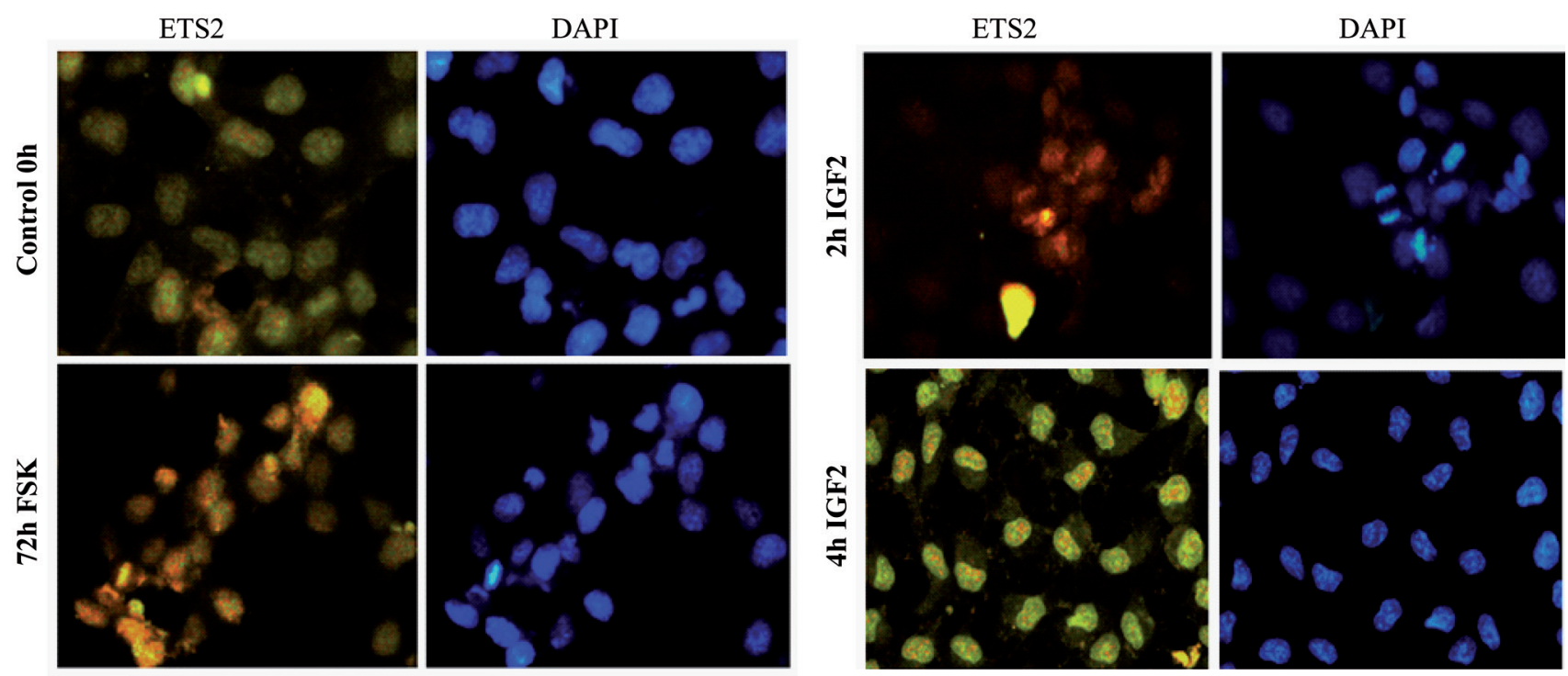

Figura 3. Translocalización nuclear del factor de transcripción ETS2 en la línea celular HTR8/SVneo durante tratamiento con FSK e IGFII. Microfotografías de fluorescencia ETS2 - Alexa fluor 488 (verde) y tinción DAPI (4',6-diamidino-2-fenilindol, azul). Las células en cultivo se privaron de SFB durante $12 \mathrm{~h}$ y posteriormente se incubaron en presencia de Forskolina $25 \mu \mathrm{M}$ por un período de 72 horas o de IGF-II 10 nM por 2 y 4 horas. Se usó como control células a 0 horas de tratamiento. Cada división de la plantilla representa $10 \mu \mathrm{m}$. Las microfotografías representan un aumento $40 \mathrm{X}$. 
actividad de la hormona en células de coriocarcinoma JEG3 y JAR (Ghosh et al., 2003). ETS1 y ETS2 son factores citoplasmáticos que al ser fosforilados en un residuo de treonina en el extremo N-terminal se activan y traslocan al núcleo, en un mecanismo que involucra la activación por la vía MAPK y regulado por AMPc (Johnson \& Jamesom, 2000). Con el fin de investigar si el factor ETS2 estaba involucrado en diferenciación, se examinó su traslocación nuclear en células tratadas con FSK e IGF-II por medio de microscopía de fluorescencia (Figura 3). (Alarcón, 2011). De manera interesante, a las 72 hr de estímulo con FSK casi todo el ETS2 se localiza en el núcleo, en concordancia con los altos niveles de secreción de hGC. Por su parte, IGF-II que se demostró induce la transcripción del gen a tiempos cortos (6 hr), también estimula la traslocación nuclear evidenciada a las 4 hr. (Figura 3). Los anteriores resultados demuestran que el IGF-II induce la transcripción de la hormona hGC mediante la activación y traslocación al núcleo del factor de transcripción ETS2. Se requieren más estudios para esclarecer el receptor involucrado y la vía de señalización desencadenada por el IGF-II, aspectos que son objeto de estudio en la actualidad en nuestro grupo de investigación.

Como se mencionó previamente, las células HTR8/SVneo poseen un alto potencial invasivo y proliferativo característico de las células evCTB y continúan diferenciándose por la vía invasiva (Figura 4). Un subtipo celular es capaz de invadir las vellosidades y la decidua materna y recibe el nombre de citotrofoblasto intersticial (inCT), mientras que las células que invaden las arterias espirales del útero se denominan citotrofoblasto endovascular (enCT). Las células inCT a medida que van erosionando el endometrio decidualizado, van perdiendo su potencial proliferativo y ganando invasividad. Se sabe que estas células no han perdido su capacidad de formar sincitio puesto que dan lugar a células gigantes multinucleadas (Kemp et al, 2002).

La caracterización de las células tratadas con FSK o IGF-II se realizó evaluando la expresión de genes marcadores de sincitialización (Huppertz et al., 2006), esto es, incremento en el mRNA de Sincitina y de Hand1 y disminución en el mRNA del gen de pluripotencia Oct4. Tomando en cuenta los resultados encontrados para los tres genes, se puede plantear que bajo las condiciones del estudio, las células HTR-8/SVneo realizan procesos de fusión para dar lugar a células gigantes multinucleadas que corresponden a sincitio no proliferativo (Figura 4).

\section{Conclusiones}

Los resultados aquí presentados representan un importante cuerpo de evidencia experimental que relacionan a los miembros del sistema IGF en la regulación de la proliferación, invasión

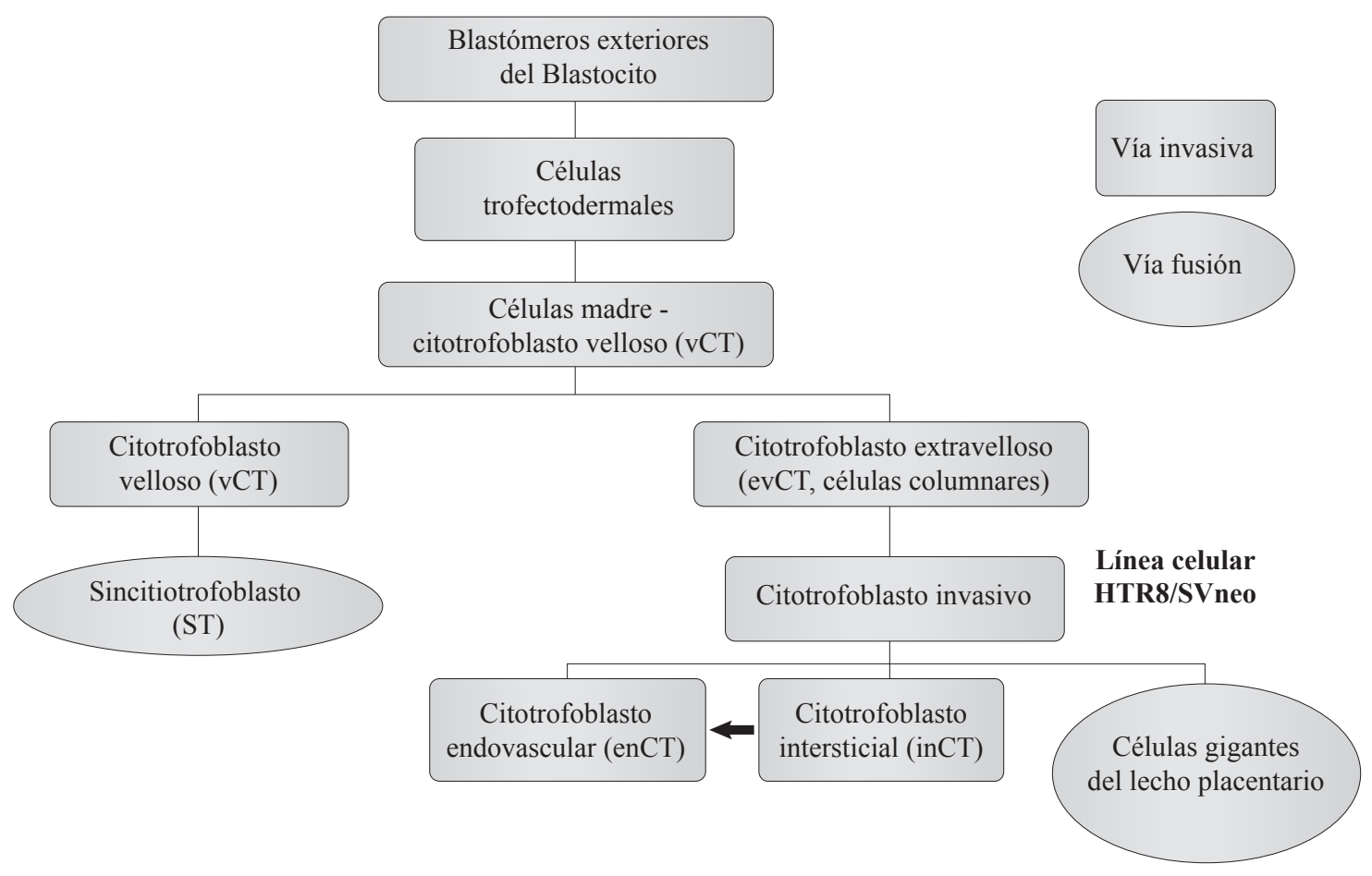

Figura 4. Esquema de la diferenciación trofoblástica.

Se muestran la vía de fusión o del citotrofoblasto velloso (vCT) y la vía invasiva o del citotrofoblasto extra-velloso (evCT). La línea celular HTR8/SVneo corresponde al fenotipo de citotrofoblasto invasivo. 
y diferenciación del trofoblasto humano. Aunque se conocía con anterioridad que los ligandos y receptores eran expresados en varios tipos celulares de la placenta, solo recientemente se ha empezado a entender su mecanismo de acción a nivel molecular y su compleja red de señalización regulada espacial y temporalmente. Varias patologías de la gestación se asocian con perturbaciones en el modo de acción de esta familia de factores de crecimiento. En el caso de la mola hidatidiforme y el coriocarcinoma, los cambios en los perfiles de expresión de IGF-II y del receptor IGF-IIR, pueden ser la base para explorar nuevos blancos terapéuticos para el tratamiento de estas patologías, así como para refinar su diagnóstico encontrando moléculas candidatas a marcadores más confiables. Por último, el hecho de que el trofoblasto comparte muchas características con células tumorales, lo hacen un modelo de investigación único donde es posible encontrar claves para comprender el origen y desarrollo del crecimiento maligno.

\section{Agradecimientos}

La autora agradece a la Universidad Nacional de Colombia y Colciencias por la financiación otorgada a los diferentes proyectos de investigación. A los integrantes del Grupo de Investigación en Hormonas que con el fruto de su trabajo contribuyeron a la realización de los estudios que aquí se presentan. Reconocimiento especial para las profesoras Stella Carrasco de Rodríguez y Adriana Umaña Pérez, a los estudiantes de posgrado Luis Eduardo Díaz, Sofía Isabel Freyre, Sandra Susana Novoa, Juan Carlos Alarcón, Andrés Felipe Vallejo y Ricardo Cabezas, a las estudiantes de pregrado Ruth Andrea Rodríguez y María Isabel Acosta. Así mismo, nuestro agradecimiento a los doctores Gunnar Norstedt y Amilcar Flores, Instituto Karolinska, Estocolmo, Suecia por su participación científica en el estudio y apoyo durante las pasantías estudiantiles realizadas durante la ejecución de estos estudios.

\section{Bibliografía}

Alarcón JC. 2011. Interacción del sistema de factores de crecimiento similares a la insulin (IGF) y la hormona gonadotropina coriónica (hGC) en la diferenciación cellular trofoblástica. Tesis Maestría Bioquímica. Universidad Nacional de Colombia.

Aronow BJ, Richardson BD, Handwerger S. 2001. Microarray analysis of trophoblast differentiation: gene expression reprogramming in key gene function categories. Physiol Genomics. 6 (2): 105-116.

Belfiore A, Frasca F, Pandini G, Sciacca L, Vigneri R. 2009. Insulin receptor isoforms and insulin receptor/insulin-like growth factor receptor hybrids in physiology and disease. Endocr Rev. 30 (6): 586-623.

Berkowitz RS \& Goldstein DP. 1998. Recent advances in gestational trophoblastic disease. Lippincott-Raven Publishers. 10 (1): 61-64.
Bischof P \& Irminger-Finger I. 2005. The human cytotrophoblastic cell, a mononuclear chameleon. Int J Biochem Cell Biol. 37:1-6.

Bischof P, Meisser A, Campana A. 2001. Biochemistry and Molecular Biology of Trophoblast Invasion. Ann NY Acad Sci, 943 (1): 157-162.

Bruchin I, Werner H. 2013. Targetin IGF-1 signaling pathways in gynecologic malignancies. Expert Opin Ther Targets. 17 (3): 307-320.

Cabezas-Pérez R, Vallejo-Pulido AF, Freyre-Bernal SI, Umaña-Pérez A, Sánchez-Gómez M. 2011. IGF-II y la gonadotropina coriónica regulan la proliferación, migración e invasión de células de trofoblasto humano. Acta Biol Colomb. 16 (1): 143-152.

Carter AM. 2007. Animal models of human placentataion - a review. Placenta. 2 (Suppl A): S41-S47.

Cortés C, Ching R, Páez P, Rodríguez A, León H, Capasso S, Lozano F, González V, Aramendiz H, Pedroza F, Galvis P, Forero E, Aragón M, Arteaga C, Bermúdez AJ. 2003. La mola hidatidiforme: un indicador de la situación sociodemográfica en salud sexual y reproductiva. Inf Quinc Epidemiol Nac. 8 (12): 193-208

Cross JC. 2000. Genetic insights into trophoblast differentiation and placental morphogenesis. Semin Cell Dev Biol. 11: 105-113.

Denley A, Cosgrove LJ, Booker GW, Wallace JC, Forbes BE. 2005. CytokineGrowth Factor Rev. 16 (4-5): 421-439.

Díaz LE, Chuan YC, Lewitt M, Fernandez-Perez L, CarrascoRodriguez S, Sanchez-Gomez M, Flores-Morales A. 2007. IGF-II regulates metastatic properties of choriocarcinoma cells through the activation of the insulin receptor. Mol Hum Reprod. 13 (8): 567-576.

Díaz, LE. 2006. Niveles de expresión del sistema de factores de crecimiento similares a la insulin (IGFs) en el desarrollo del tejido molar, Tesis Doctorado Química, Universidad Nacional de Colombia.

El-Shewy H, Lee M, Obeid L, Jaffa A, Luttrell L. 2007. The insulin-like Growth Factor type 1 and Insulin-like Growth Factor type 2/Mannose-6-phosphate Receptors independently regulate ERK1/2 activity in HEK293 cells. J Biol Chem. 282 (36): 26150-26157.

Ferretti C, Bruni L, Dangles-Marie V, Pecking AP, Bellet D. 2007. Molecular circuits shared by placental and cancer cells, and their implications in the proliferative, invasive and migratory capacities of trophoblasts. Hum Reprod Update, 13 (2): 121-141.

Forbes K, Westwood M, Baker PN, Aplin JD. 2008. Insulin like growth factor I and II regulate the life cycle of trophoblast in the developing human placenta. Am J Physiol Cell Physiol. 294 (6): C1313-22.

Frasca F, Pandini G, Sciacca L, Pezzino V, Squatrito S, Belfiore A, Vigneri R. 2008. The role of insulin receptors and 
IGF-I receptors in cancer and other diseases. Arch Physiol Biochem. 114 (1): 23-27.

Freyre SI. 2010. Papel del sistema de factores de crecimiento similares a la insulina (IGF) en la regulación del crecimiento y diferenciación trofoblástica. Tesis Maestría Bioquímica. Universidad Nacional de Colombia.

Gallagher EJ, LeRoith D. 2011. Minireview: IGF, insulin and cancer. Endocrinology. 152 (7): 2546-2551.

Ghosh D, Ezashi T, Ostrowski MC, Roberts RM. 2003. A central role for Ets-2 in the transcriptional regulation and cyclic adnosine 5-monophosphate responsiveness of the human chorionic gonadotropin-beta subunit gene. Mol Endocrinol. 17 (1): $11-26$

Graham CH, Hawley TS, Hawley RG, MacDougall JR, Kerbel RS, Khoo N, Lala PK. 1993. Establishment and Characterization of First Trimester Human Trophoblast Cells with Extended Lifespan. Exp Cell Res. 206 (2): 204-211.

Graham CH \& Lala PK. 1992. Mechanisms of placental invasion of the uterus and their control. Biochem Cell Biol, 70 (1011): $867-874$

Han VK, Carter AM. 2000. Spatial and temporal patterns of expression of messenger RNA for insulin-like growth factors and their binding proteins in the placenta of man and laboratory animals. Placenta. 21 (4): 289-305.

Hanahan D \& Weinberg RA. 2000. The hallmarks of cancer. Cell. 100:57-70.

Handwerger S. 2010. New insights into de human cytotrophoblast differentiation. Mol Cell Endocrinol. 323: 94-104.

Huppertz B, Bartz C, Kokozidou. 2007. Trophoblast fusión: fusogenic proteins, syncytins and ADAMs, and other prerequisites for syncytial fusion. Micron. 37 (6): 509-517.

Johnson W \& Jameson JL. 2000. Role of Ets2 in cyclic AMP regulation of the human chorionic gonadotropin (beta) promoter. Mol Cell Endocrinol. 165 (1-2):17-24.

Kemp B, Kertschanska S, Kadyrov M, Rath W, Kaufmann P, Hupperz B. 2002. Invasive depth of extravillous trophoblast correlates with cellular phenotype: A comparison of intraand extra-uterine implantation sites. Histochem Cell Biol. 117: 401-414.

Kimura AP, Sizova D, Handwerger S, Cooke NE, Liebhaber SA. 2007. Epigenetic activation of the human growth hormone gene cluster during placental cytotrophoblast differentiation. Mol Cell Biol. 27: 6555-6568.

Kliman, HJ and Feinberg RF. 1990. Human trophoblastextracellular matrix (ECM) interactions in vitro: ECM thickness modulates morphology and proteolytic activity. Proc Natl Acad Sci U S A, 87 (8): 3057-3061.

Kreiling J, Byrds J, MacDonald R. 2005. Domain Interactions of the Mannose 6-Phosphate/Insuline-like Growth Factor II Receptor. J Biol Chem. 280 (22): 21067-21077.
Lala P.K, Hamilton GS, Athanassiades A. 1998. Role of growth factors and other placental signals in extravillous trophoblast cell function: A review. Placenta. 19: 327-339.

LeRoith D \& Roberts C. 2003. The insulin-like growth factor system and cancer. Cancer Letters. 195 (2):127-137.

LeRoith D, Werner H, Neuenschwander S, Kalebic T \& Helman LJ. 1995. The role of the insulin-like growth factor-I receptor in cancer. Ann NY Acad Sci. 766: 402-406.

McKinnon T, Chakraborty C, Gleeson LM, Chidlac P, Lala PK. 2001. Stimulation of Human Extravillous Trophoblast Migration by IGF-II Is Mediated by IGF Type 2 Receptor Involving Inhibitory G Protein(s) and Phosphorylation of MAPK. J Clin Endocrinol Metab. 86 (8): 3665-3674.

Murphy SK, Huang Z, Wen Y, Spillman MA, Whitaker RS, Simel LR, Nichols TD, Marks JR, Berchuck A. 2006. Frequent IGF2/H19 doamin epigenetic alterations and elevated IGF2 expression in epithelial ovarian cancer. Mol Cancer Res. 4 (4): 283-292.

Pandini G, Frasca F, Mineo R, Sciacca L, Vigneri R, Belfiore A. 2002. Insulin/insulin-like growth factor I hybrid receptors have different biological characteristics depending on the insulin receptor isoform involved. J Biol Chem. 277 (42): 39684-39695.

Pavelic K, Bukovic D, Pavelic J. 2002. The role of insulin-like growth factor 2 and its receptors in human tumors. Mol Med. 8 (12): 771-780.

Pinzón ML, Ortiz BL, Sánchez de Gómez M. 2007. Relación de la expression de mARN de las metaloproteinasas 2 y 9 y el inhibidor TIMP-1 en mola hidatidiforme completa. Rev Col Quim. 36 (2) 137-149.

Samani AA, Yakar S, LeRoith D, Brodt P. 2007. The role of the IGF system in cancer growth and metastasis: overview and recent insights. Endocr Rev. 28 (1): 20-47.

Sánchez de Gómez M. 2006. Significado biológico del eje hormona de crecimiento $(\mathrm{GH}) /$ Factor de crecimiento similar a la insulin (IGF). Rev Acad Colomb Cienc. 30 (114): 101-108.

Scott IC, Anson-Cartwright L, Riley P, Reda D, Cross JC. 2000. The Hand1 basic helix-loop-helix transcription factor regulates trophoblast differentiation in a multiple mechanisms. Mol Cell Biol. 20, 530-541.

Seckl MJ, Fisher RA, Salerno G, Rees H, Paradinas FJ, Foskett M, Newlandas ES. 2000. Choriocarcinoma and partial hydatidiform moles. Lancet. 356 (9223): 36-39.

Singh P, Alex JM, Bast F. 2014. Insulin receptor (IR) and insulinlike growth factor receptor 1 (IGF-1R) signaling systems: novel treatment strategies. Med Oncol. 31 (1): 805.

Silva C, Kloth M, Lyons C, Dunn C. and Kirk S. 2002 Intracellular signaling by growth hormone variant (GH-V). Growth Hormone \& IGF Research, 12: 374-380.

Staun-Ram E, Goldman S, Gabarin D and Shaley E. 2004. Expression and importance of matrix metalloproteinase 
2 and 9 (MMP-2 and -9) in human trophoblast invasion. Reprod Biol Endocrinol. 2 (1): 59

Vallejo AF, Flores-Morales A, Norstedt G, Sanchez-Gomez M. 2014. Down-regulation of Insulin-like growth factor I receptor and Insulin receptor by siRNA reduce the invasiveness of trophoblast cells: Role of MMP-9. To be submitted.

Vallejo AF. 2011. Importancia de los receptors híbridos receptor de insulina/receptor del factor de crecimiento similar a la insulin tipo I (InsR/IGF-IR) en las redes de señalización del sistema IGF. Tesis Doctorado Química, Universidad Nacional de Colombia.

Yang M, Lei ZM \& Rao Ch V. 2003. The central role of human chorionic gonadotropin in the formation of human placental syncytium. Endocrinol, 144: 1108-1120.

Zygmunt M, McKinnon T, Herr F, Lala PK, Han VK. 2005. HCG increases trophoblast migration in vitro via the insulin-like growth factor-II/mannose- 6 phosphate receptor. Mol. Hum. Reprod. 11 (4): 261-267 